\title{
A Novel Dual-Permanent-Magnet-Excited Machine with Flux Strengthening Effect for Low-Speed Large-Torque Applications
}

\author{
Yujun Shi ${ }^{1,2}$ and Linni Jian 1,2,* \\ 1 Department of Electrical and Electronic Engineering, Southern University of Science and Technology, \\ Shenzhen 518055, China; shiyj3@mail.sustc.edu.cn \\ 2 Shenzhen Key Laboratory of Electric Direct Drive Technology, Shenzhen 518055, China \\ * Correspondence: jianln@sustc.edu.cn; Tel.: +86-755-8801-8525
}

Received: 8 December 2017; Accepted: 4 January 2018; Published: 8 January 2018

\begin{abstract}
This paper proposes a novel dual-permanent-magnet-excited (DPME) machine. It employs two sets of permanent magnets (PMs). One is on the rotor, the other is on the stator with PM arrays. When compared with the existing DPME machines, not all of the PMs are located in the slots formed by the iron teeth. Specifically, the radially magnetized PMs in the arrays are located under the short iron teeth, while the tangentially magnetized PMs are located in the slots formed by the long stator iron teeth and the radially magnetized PMs. Each long stator iron tooth is sandwiched by two tangentially magnetized PMs with opposite directions, thus resulting in the flux strengthening effect. The simulation analysis indicates that the proposed machine can offer large back EMF with low THD and large torque density with low torque ripple when compared with Machine I from a literature. Meanwhile, by comparison, the proposed machine has great potential in improving the power factor and efficiency.
\end{abstract}

Keywords: field modulation; permanent magnet (PM) machine; vernier machine; direct-drive; low-speed large torque; torque density

\section{Introduction}

With the absence of mechanical gearboxes, permanent magnet (PM) direct-drive machines have attracted more and more attention in recent years with the rapid increase of low-speed large-torque (LSLT) applications, such as wind power generation, robotics, ship propulsion, electrical vehicles, wave energy conversion, and railway traction [1-3]. In PM direct-drive machines, field-modulated permanent magnet (FMPM) machines are promising candidates for these LSLT applications because FMPM machines working based on the so-called "magnetic gearing effect" possess the inherent merits of high torque density and high efficiency [4]. Integrated magnetic-geared machines (IMGMs) and PM vernier machines are the most common ones in FMPM machines. However, since there exist multi-layer air-gaps [5-11], IMGMs suffer from complex mechanical structures, thus resulting in a decrease in practicality. On the contrary, PM vernier machines with simple structures are favored and widely investigated by researchers [12-20]. Only one set of PMs is employed in all of the aforementioned PM vernier machines, and the PMs are either on the stator or on the rotor. Namely, one kind of machine is rotor type (RT) [12-14], and the other belongs to stator type (ST) [17-23]. The torque capability of these PM vernier machines is limited, as the precious spaces in stator and rotor for the assembly of PMs are not made full use of.

In order to break through the limitation of the torque capability, novel PM machines with two sets of PMs on both the stator and rotor were proposed in [2,21-24]. This kind of machine was first named "dual-permanent-magnet-excited (DPME) machine" in 2013 [25], where "bi-directional 
field modulation effect (BFME)" was first proposed to elaborate the operating principle. According to the "BFME", it is easy to know the pole-pair number (PPN) relationship between the two sets of PMs and armature windings, and how to design this kind of machine. References $[25,26]$ have confirmed that DPME machines can offer lager torque than both ST and RT PM vernier machines; performance between DPME machines with fewer stator poles and fewer rotor poles were compared in [27], which has point out that the DPME machines with fewer rotor poles have better torque capability; surface response methodology was used to optimize the design of a DPME machine in [28]; DPME machines with Halbach PM arrays were proposed and analyzed on behalf of further improving the torque in [26,29-31]. In terms of all the aforementioned DPME machines with PM arrays or without PM arrays, they have something in common in the structure, that is, all of the PMs are located in the slots formed by the iron teeth, and consequent poles are applied to these machines in order to artfully realize the BFME. Obviously, there is a fact that the usage of PMs increases when adopting BFME to design DPME machines. And rare-earth PMs are used in most aforementioned DPME machines. As reported in [32-36], with the rapid increase of the demand of rare-earth PMs, there is a worldwide concern, because nearly $96 \%$ of rare-earth elements' production is provided by China, the cost of rare-earth PM is so high and the supply is easily restricted by exporting countries. Therefore, in addition to the pursuit of the torque density when designing DPME machines, the intensity of PM utilization $(\mathrm{kg} / \mathrm{kW})$ also needs to be considered. However, the intensity of PM utilization of most DPME machines from the cited literatures is not taken into account.

A novel DPME machine will be proposed in this paper. Two sets of PMs are also employed in the stator and rotor, and its rotor also adopts the consequent poles. What is the significant difference from all the DPME machines in the cited references is that not all PMs are in the slots. Specifically, the stator PMs magnetized along radial direction are located under the short stator iron teeth, while the stator PMs magnetized tangentially are located in the slots formed by the long stator iron teeth and the stator PMs magnetized along radial direction. Each long stator iron tooth is clamped by two tangentially magnetized PMs with opposite directions. Thus, the flux strengthening effect will occur in this machine and the air-gap flux density will be improved. The performance of the proposed machine, including torque density, intensity of PM utilization, power factor, losses, efficiency, etc., will be analyzed and compared with a DPME machine from a literature by using finite element method (FEM). The organization of this paper is as follows. In Section 2, the configuration of the proposed machine will be introduced in detail. In Section 3, the working principle will be revealed. In Section 4, different PM magnetization patterns will be studied, and electromagnetic performance of the proposed machine with optimal magnetization pattern will be analyzed by the FEM simulation. In Section 5, comparative study between the proposed machine and a DPME machines from a literature will be performed in order to confirm the flux strengthening effect and compare their performance. Finally, the conclusions will be drawn in Section 6.

\section{Machine Configuration}

Figure 1 shows the basic configuration of the proposed DPME machine. It consists of a rotor and a stator. The rotor PMs are inserted into the rotor core. All of the rotor PMs are magnetized along either radial outward direction or radial inward direction. The stator is composed of a slotted stator core wound with three-phase armature windings and several duplicate PM arrays. It is worth noting that the stator core has a number of stator iron teeth with unequal lengths, and the long and short stator iron teeth are arranged alternately along the circumference. For each PM array, it is constituted of three PMs and their magnetization directions differ from each other. Wherein, the stator PM under the short stator iron tooth is magnetized along either radial outward direction or radial inward direction, while the other two PMs are tangentially magnetized with opposite directions. 


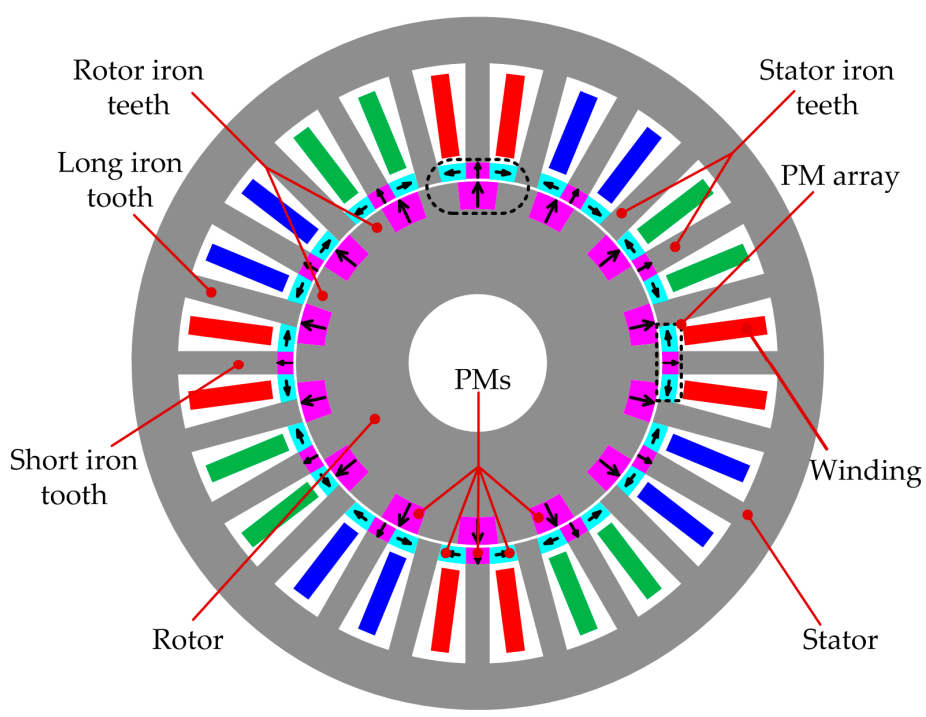

Figure 1. Basic configuration of the proposed dual-permanent-magnet-excited (DPME) machine.

In the proposed machine, each rotor PM and its adjacent rotor iron tooth form a pair of magnet poles. Thus, the PPN of the rotor PMs denoted by $p_{1}$ is the same as the number of the rotor iron teeth. Similar to the rotor PMs, each stator PM magnetized along the radial direction and its adjacent long stator iron tooth form a pair of magnet poles. But, unlike the rotor PMs, the stator PM magnetized along the radial direction is separated from a long stator iron teeth by a tangentially magnetized PM. Therefore, the PPN of the stator PMs denoted by $p_{2}$ is equal to the number of the long rotor iron teeth, and half the number of the stator iron teeth or stator slots. In addition every two tangentially magnetized PMs with opposite directions clamp a long stator iron tooth, which can cause the flux strengthening effect and improve the air-gap flux density.

The main features of the proposed machine are summarized as follows:

- The proposed machine employs two sets of PMs, one with PM arrays on the stator and the other on the rotor. Based on BFME, it can achieve the effective coupling between the magnetic field excited by the armature windings and those excited by the two sets of PMs. As a result, the machine can offer much higher torque capability.

- Both the stator and rotor magnetic poles adopt the consequent poles. Especially for the stator magnetic pole, a pair of magnet poles is formed by a PM under a short iron tooth and its adjacent long iron tooth. What is different from the rotor magnetic poles is that the PM under the short iron tooth is separated from a long iron teeth by a PM magnetized tangentially.

- The arrangement of a long stator iron tooth and two tangentially magnetized PMs with opposite directions is capable of strengthening the PM fluxes, hence improving the flux density.

- For the stator teeth, there are PMs under the short stator iron teeth. Since the relative permeability of PMs is close to that of the air, the field modulating effect of the short stator iron teeth is weakened, and the long stator iron teeth mainly serves as the field modulating teeth. Thus, the number of stator iron teeth serving as field modulating teeth can be considered to be half the number of the stator iron teeth. For the rotor, the rotor iron teeth play the role of field modulating teeth.

- It is interesting that the number of the rotor and stator iron teeth with field modulating effect is equal to the PPN of the rotor PMs and stator PMs, respectively.

\section{Working Principle}

The working principle of the proposed DPME machine is based on the so-called BFME. Similar to the function of ferromagnetic pieces in magnetic gears, the long stator iron teeth and the rotor iron 
teeth serving as field modulating teeth play the role of modulating magnetic fields that are excited by different magnetic sources. So, the magnetic fields excited by the rotor PMs, stator PMs, and armature windings can be modulated into abundant field harmonics in the air-gap. Harmonics with exactly the same PPN and rotational speed will couple together to produce stable electromagnetic torque. To reveal the working principle of the proposed machine clearly, the field harmonics excited by rotor PMs, stator PMs, and armature windings are investigated in detail.

Firstly, the air-gap flux density due to rotor PMs is investigated. The magnetomotive force (MMF) of rotor PMs can be expressed by its Fourier series:

$$
\begin{aligned}
F_{P M}^{R}\left(\theta_{s}, t\right) & =\sum_{m=1,3,5 \ldots}^{\infty} \frac{F_{P M}^{R}}{m} \cos \left(m p_{1} \theta_{r}\right)=\sum_{m=1,3,5 \ldots}^{\infty} \frac{F_{P M}^{R}}{m} \cos \left[m p_{1}\left(\theta_{s}-\theta_{m}\right)\right] \\
& =\sum_{m=1,3,5 \ldots}^{\infty} \frac{F_{P M}^{R}}{m} \cos \left[m p_{1}\left(\theta_{s}-\Omega_{1} t\right)\right]
\end{aligned}
$$

where $F_{P M}^{R}$ is the amplitude of the fundamental component of the rotor PM MMF; $\theta_{s}, \theta_{r}$, and $\theta_{m}$ are the mechanical angles of the winding MMF, the rotor PM MMF and the rotor position, respectively, the details of which are shown in Figure $2 ; \theta_{m}=\Omega_{1} t$, and $\Omega_{1}$ the speed of the rotor.

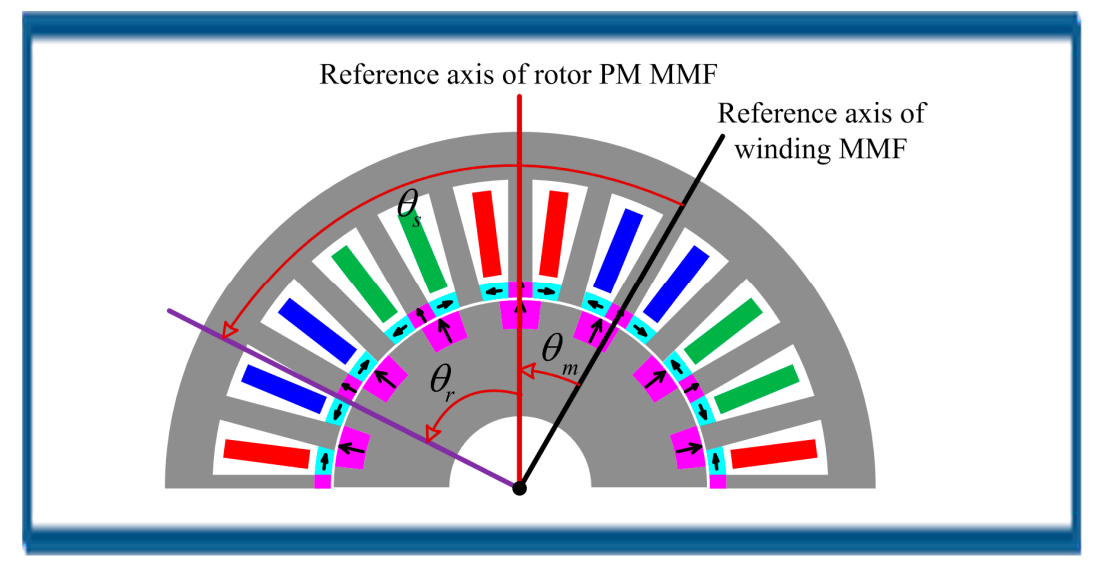

Figure 2. Definition of mechanical angles.

Since the number of the long stator iron teeth serving as field modulating teeth is equal to the PPN of the stator PMs, the air-gap permeance function due to the long stator teeth can be expressed by its Fourier series:

$$
\lambda_{S}\left(\theta_{S}\right)=\lambda_{S}^{0}+\sum_{k=1}^{\infty} \lambda_{S}^{k} \cos \left(k p_{2} \theta_{S}\right)
$$

where $\lambda_{S}^{0}$, and $\lambda_{S}^{k}$ are the constant component and the amplitude of the $k$ th harmonic in (2), respectively.

The air-gap flux density produced by the rotor PMs, $B_{P M}^{R}\left(\theta_{s}, t\right)$, can be obtained by calculating the product of $F_{P M}^{R}\left(\theta_{s}, t\right)$ and $\lambda_{S}\left(\theta_{s}\right)$,

$$
\begin{gathered}
B_{P M}^{R}\left(\theta_{s}, t\right)=\sum_{m=1,3,5 \ldots}^{\infty} \frac{F_{P M}^{R} \lambda_{S}^{0}}{m} \cos \left[m p_{1}\left(\theta_{s}-\Omega_{1} t\right)\right] \\
+\sum_{m=1,3,5 \ldots}^{\infty} \sum_{k=1}^{\infty} \frac{F_{P M}^{R} \lambda_{S}^{k}}{2 m} \cos \left[\left(m p_{1}+k p_{2}\right)\left(\theta_{s}-\frac{m p_{1} \Omega_{1}}{m p_{1}+k p_{2}} t\right)\right] \\
+\sum_{m=1,3,5 \ldots}^{\infty} \sum_{k=1}^{\infty} \frac{F_{P M}^{R} \lambda_{S}^{k}}{2 m} \cos \left[\left(m p_{1}-k p_{2}\right)\left(\theta_{s}-\frac{m p_{1} \Omega_{1}}{m p_{1}-k p_{2}} t\right)\right]
\end{gathered}
$$

From (3), we can see that the flux density produced by the rotor PMs contains three groups. One is the original harmonics with PPN $=m p_{1}$, and these harmonics rotate with the same speed 
of rotor. The other two groups are harmonics with PPN $=\left|m p_{1}+k p_{2}\right|$ and PPN $=\left|m p_{1}-k p_{2}\right|$, and the corresponding speeds are $m p_{1} \Omega_{1} /\left(m p_{1}+k p_{2}\right)$ and $m p_{1} \Omega_{1} /\left(m p_{1}-k p_{2}\right)$, respectively. These two harmonic groups are generated due to the field modulating effect of the long stator iron teeth. The detailed harmonic PPNs and corresponding speeds are listed in Table 1.

Table 1. Field harmonics excited by the rotor permanent magnets (PMs).

\begin{tabular}{ccc}
\hline Group No. & PPN & Speed \\
\hline 1 & $\left|m p_{1}\right|$ & $\Omega_{1}$ \\
2 & $\left|m p_{1}+k p_{2}\right|$ & $m p_{1} \Omega_{1} /\left(m p_{1}+k p_{2}\right)$ \\
3 & $\left|m p_{1}-k p_{2}\right|$ & $m p_{1} \Omega_{1} /\left(m p_{1}-k p_{2}\right)$ \\
\hline
\end{tabular}

Secondly, the air-gap flux density due to stator PMs is studied. Similarly, the MMF of stator PMs can be expressed by its Fourier series:

$$
F_{P M}^{S}\left(\theta_{S}\right)=\sum_{m=1,3,5 \ldots}^{\infty} \frac{F_{P M}^{S}}{m} \cos \left(m p_{2} \theta_{S}\right)
$$

where $F_{P M}^{S}$ is the amplitude of the fundamental component of the stator MMF.

Since the number of the rotor iron teeth serving as field modulating teeth is equal to the PPN of the rotor PMs, the air-gap permeance function due to the rotor iron teeth can be expressed by its Fourier series:

$$
\begin{aligned}
\lambda_{R}\left(\theta_{s}, t\right) & =\lambda_{R}^{0}+\sum_{k=1}^{\infty} \lambda_{R}^{k} \cos \left(k p_{1} \theta_{s}-k p_{1} \theta_{m}\right) \\
& =\lambda_{R}^{0}+\sum_{k=1}^{\infty} \lambda_{R}^{k} \cos \left(k p_{1} \theta_{s}-k p_{1} \Omega_{1} t\right)
\end{aligned}
$$

where $\lambda_{R}^{0}$, and $\lambda_{R}^{k}$ are the constant component and the amplitude of the $k$ th harmonic in (5), respectively.

The air-gap flux density excited by the stator PMs, $B_{P M}^{S}\left(\theta_{s}, t\right)$, can be obtained by multiplying $F_{P M}^{S}\left(\theta_{S}\right)$ and $\lambda_{R}\left(\theta_{s}, t\right)$.

$$
\begin{gathered}
B_{P M}^{S}\left(\theta_{S}, t\right)=\sum_{m=1,3,5 \ldots}^{\infty} \frac{F_{P M}^{S} \lambda_{S}^{0}}{m} \cos \left(m p_{2} \theta_{S}\right) \\
+\sum_{m=1,3,5 \ldots}^{\infty} \sum_{k=1}^{\infty} \frac{F_{P M}^{S} \lambda_{S}^{k}}{2 m} \cos \left[\left(m p_{2}+k p_{1}\right)\left(\theta_{S}-\frac{k p_{1} \Omega_{1}}{m p_{2}+k p_{1}} t\right)\right] \\
+\sum_{m=1,3,5 \ldots k=1}^{\infty} \sum_{k=1}^{\infty} \frac{F_{P M}^{R} \lambda_{S}^{k}}{2 m} \cos \left[\left(m p_{2}-k p_{1}\right)\left(\theta_{S}+\frac{k p_{1} \Omega_{1}}{m p_{2}-k p_{1}} t\right)\right]
\end{gathered}
$$

From (6), we can see that the flux density produced by the stator PMs can be divided into three groups. The static harmonics with PPN $=m p_{2}$ are the original harmonics of stator PMs. The rotating harmonics with PPN $=\left|m p_{2}+k p_{1}\right|$ and PPN $=\left|m p_{2}-k p_{1}\right|$, and the corresponding speeds are $k p_{1} \Omega_{1} /\left(m p_{2}+k p_{1}\right)$ and $-k p_{1} \Omega_{1} /\left(m p_{2}-k p_{1}\right)$, respectively. The negative notation means that these harmonics rotate opposite to the rotor direction. These two rotating harmonic groups are generated due to the field modulating effect of the rotor iron teeth. The detailed harmonic PPNs and corresponding speeds are listed in Table 2.

Table 2. Field harmonics excited by the stator PMs.

\begin{tabular}{ccc}
\hline Group No. & PPN & Speed \\
\hline 1 & $\left|m p_{2}\right|$ & 0 \\
2 & $\left|m p_{2}+k p_{1}\right|$ & $k p_{1} \Omega_{1} /\left(m p_{2}+k p_{1}\right)$ \\
3 & $\left|m p_{2}-k p_{1}\right|$ & $-k p_{1} \Omega_{1} /\left(m p_{2}-k p_{1}\right)$ \\
\hline
\end{tabular}


Finally, the magnetic field excited by armature windings is analyzed. The MMF produced by three-phase sinusoidal alternating current (AC) is given by

$$
\left\{\begin{array}{l}
F_{w}\left(\theta_{s}, t\right)=\sum_{m=1,5,7 \ldots}^{\infty} F_{w} k_{w}^{m} \cos \left(m p_{3} \theta_{s}-h \omega t\right) \\
F_{w}=\frac{3 \sqrt{2} N I}{\pi p_{3}} \\
h=\left\{\begin{array}{cc}
1 & m=6 n-1, n=0,1,2 \ldots \\
-1 & m=6 n+1, n=0,1,2 \ldots
\end{array}\right.
\end{array}\right.
$$

where $k_{w}^{m}$ is the winding factor of the $m$ th harmonic; $p_{3}$ is the PPN of the armature windings; $\omega$ is the angular frequency of the currents; $N$ is the total turns of the single phase winding; and, $I$ is the effective value of the currents.

The magnetic field excited by armature windings can be modulated simultaneously by the long stator iron teeth and rotor teeth. By calculating the product of $F_{w}\left(\theta_{s}, t\right), \lambda_{S}\left(\theta_{s}\right)$ and $\lambda_{R}\left(\theta_{s}, t\right)$, the flux density excited by the armature currents can be obtained as follows:

$$
\begin{aligned}
& B_{w}\left(\theta_{s}, t\right)=F_{w}\left(\theta_{s}, t\right) \lambda_{S}\left(\theta_{s}\right) \lambda_{R}\left(\theta_{s}, t\right) \\
& =A \sum_{m=1,5,7 \ldots}^{\infty} \cos \left[m p_{3}\left(\theta_{s}-\frac{h \omega}{m p_{3}} t\right)\right] \\
& +B \sum_{m=1,5,7 \ldots}^{\infty} \sum_{k=1}^{\infty} \cos \left[\left(m p_{3} \pm k p_{2}\right)\left(\theta_{s}-\frac{h \omega}{m p_{3} \pm k p_{2}} t\right)\right] \\
& +C \sum_{m=1,5,7 \ldots}^{\infty} \sum_{k=1}^{\infty} \cos \left[\left(m p_{3} \pm k p_{1}\right)\left(\theta_{s}-\frac{\left(h \omega \pm k p_{1} \Omega_{1}\right)}{m p_{3} \pm k p_{1}} t\right)\right] \\
& +D \sum_{m=1,5,7 \ldots}^{\infty} \sum_{k_{1}=1}^{\infty} \sum_{k_{2}=1}^{\infty} \cos \left[\left(m p_{3} \pm k_{1} p_{2} \pm k_{2} p_{1}\right)\left(\theta_{s}-\frac{\left(h \omega \pm k_{2} p_{1} \Omega_{1}\right)}{m p_{3} \pm k_{1} p_{2} \pm k_{2} p_{1}} t\right)\right]
\end{aligned}
$$

where $A, B, C$, and $D$ are coefficients in (8). It is necessary to explain that they are not given in (8) in order to reduce the length of the formula, and both $k_{1}$ and $k_{2}$ are positive integers.

From (8), we can see that the flux density excited by armature windings can be categorized into four groups. The first group is the original harmonics that are neither modulated by the stator teeth nor modulated by the rotor teeth, the second and the third groups are the armature fields modulated by the stator teeth and the rotor teeth, respectively, the last group is harmonics modulated by both the stator teeth and the rotor teeth. The detailed harmonic PPNs and corresponding speeds are listed in Table 3.

Table 3. Field harmonics excited by the armature windings.

\begin{tabular}{ccc}
\hline Group No. & PPN & Speed \\
\hline 1 & $\left|m p_{3}\right|$ & $h \omega / m p_{3}$ \\
2 & $\left|m p_{3} \pm k p_{2}\right|$ & $h \omega /\left(m p_{3} \pm k p_{2}\right)$ \\
3 & $\left|m p_{3} \pm k p_{1}\right|$ & $\left(h \omega \pm k p_{1} \Omega_{1}\right) /\left(m p_{3} \pm k p_{1}\right)$ \\
4 & $\left|m p_{3} \pm k_{1} p_{2} \pm k_{2} p_{1}\right|$ & $\left(h \omega \pm k_{2} p_{1} \Omega_{1}\right) /\left(m p_{3} \pm k_{1} p_{2} \pm k_{2} p_{1}\right)$ \\
\hline
\end{tabular}

In order to output stable electromagnetic torque, the two interacted field harmonics should have the same PPN and the same rotating speed. Only the highest harmonic components are taken into consideration when $m=k=h=1$. It can be found that if

$$
\left\{\begin{array}{l}
p_{3}+p_{2}=p_{1} \\
\omega=p_{1} \Omega_{1}
\end{array}\right.
$$

there exist effective field harmonics with exactly the same PPN and rotational speed, as shown in Table 4. It should be noted that the same color in Table 4 represents effective field harmonics with exactly the same PPN and rotational speed. 
Table 4. The effective field harmonics.

\begin{tabular}{ccc}
\hline \multicolumn{3}{c}{ Field Harmonics Excited by the Rotor PMs } \\
\hline Group No. & PPN & Speed \\
\hline 1 & $p_{1}$ & $\Omega_{1}$ \\
2 & $p_{3}$ & $p_{1} \Omega_{1} / p_{3}$
\end{tabular}

Field Harmonics Excited by the Stator PMs

\begin{tabular}{ccc}
3 & $p_{2}$ & 0 \\
4 & $p_{3}$ & $p_{1} \Omega_{1} / p_{3}$ \\
\hline
\end{tabular}

Field Harmonics Excited by the Armature Windings

\begin{tabular}{ccc}
5 & $p_{3}$ & $\omega / p_{3}$ \\
6 & $p_{1}$ & $\omega / p_{1}$ \\
7 & $p_{2}$ & $-\left(\omega-p_{1} \Omega_{1}\right) / p_{2}$ \\
\hline
\end{tabular}

\section{Performance Analysis}

The performance of the proposed DPME machine is analyzed by using the 2D FEM. In this study, $p_{1}$ and $p_{2}$ are selected for 14 and 12 . The key parameters of the proposed machine are listed in Table 5. The slot electrical potential star vectogram and winding connection are illustrated in Figure 3. The 2D FEM models are built based on the parameters in Table 5 in Jmag-Designer software. As shown in Figure 4, 2D FEM mesh model is built. A five-layer mesh in the air-gap region is generated. The number of elements and nodes is $48,602,26,176$, respectively. The average mesh quality that is offered by Jmag-Designer software is about 0.75 (the best mesh quality in this software corresponds to 1$)$. The time step is set to about $5 / 7 \mathrm{~ms}$, according to the electric cycle $(1 / 28 \mathrm{~s})$ when the machine rotates at the speed of $120 \mathrm{r} / \mathrm{min}$. It is worth noting that all of the simulation analysis later in this section is based on this mesh model.

Table 5. Key parameters of the proposed machine.

\begin{tabular}{cccc}
\hline PPN of rotor PMs & 14 & Electric resistivity of PMs & $1.44 \times 10^{-6} \Omega \cdot \mathrm{m}$ \\
PPN of stator PMs & 12 & Material of iron core & $50 \mathrm{H} 470$ \\
PPN of armature windings & 2 & Outer diameter of stator & $150 \mathrm{~mm}$ \\
Number of stator slots & 24 & Thickness of stator yoke & $10 \mathrm{~mm}$ \\
Phase number & 3 & Inner diameter of stator & $80 \mathrm{~mm}$ \\
Turns per coil in series & 12 & Thickness of stator PMs & $3.5 \mathrm{~mm}$ \\
Phase resistance ${ }^{1}$ & $0.6 \Omega$ & Air-gap length & $0.6 \mathrm{~mm}$ \\
Effective value of current, $I$ & $3 \mathrm{~A}$ & Thickness of rotor PMs & $6 \mathrm{~mm}$ \\
Rated speed & $120 \mathrm{r} / \mathrm{min}$ & Outer diameter of rotor yoke & $66.8 \mathrm{~mm}$ \\
Remanence of PMs & $1.2 \mathrm{~T}$ & Inner diameter of rotor yoke & $30 \mathrm{~mm}$ \\
Relative PM permeability & 1.05 & Effective axial length & $60 \mathrm{~mm}$ \\
\hline
\end{tabular}

${ }^{1}$ Phase resistance does not contain end-winding resistance.

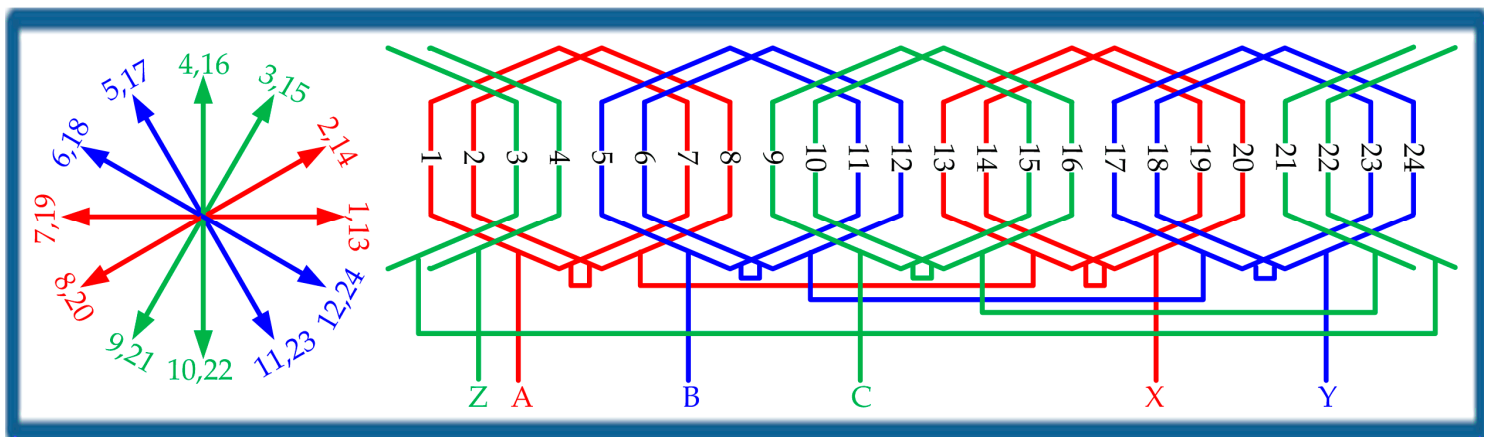

Figure 3. Slot electrical potential star vectogram and winding connection. 


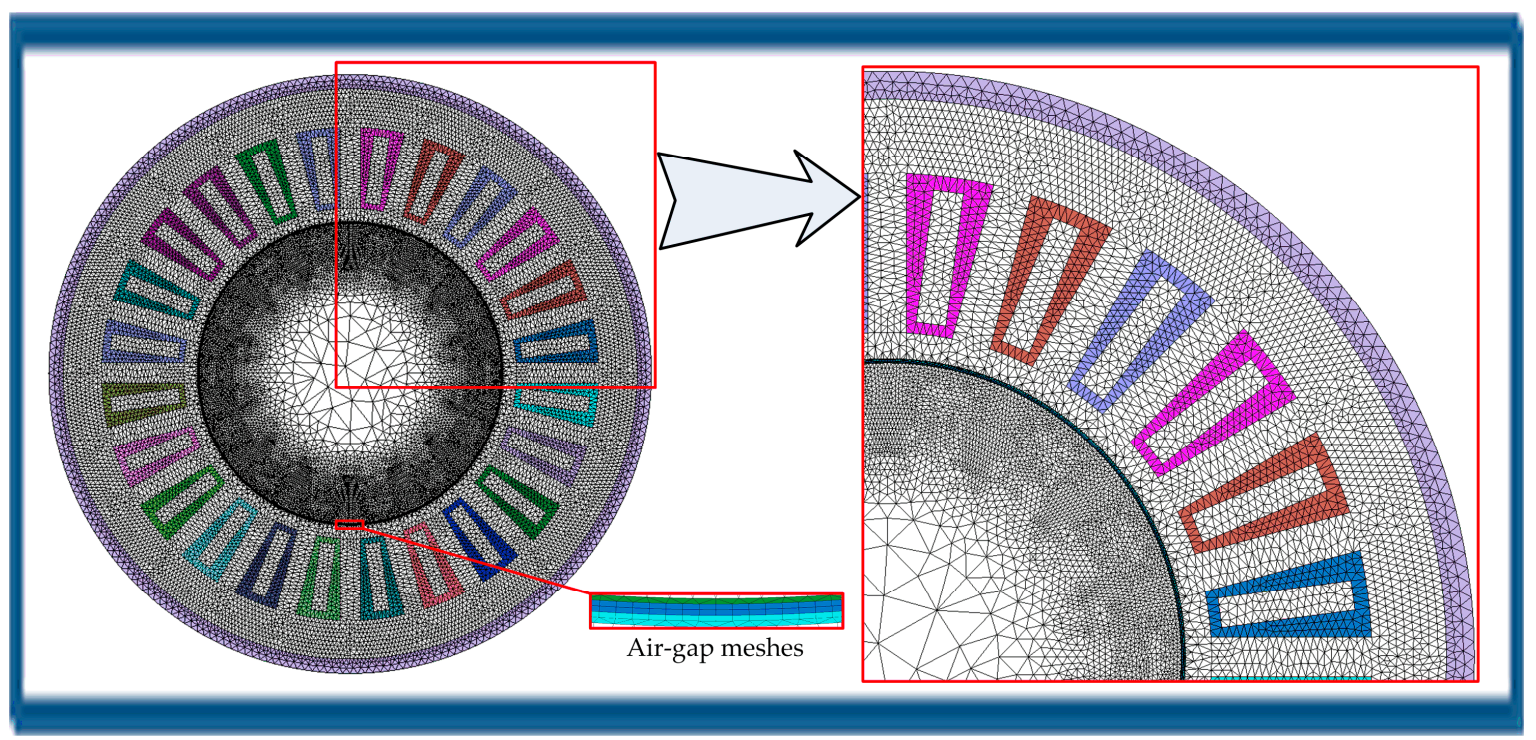

Figure 4. Mesh model of the proposed machine.

\subsection{Choice of Optimal Magnetization Pattern}

As described in Section 2, the radial PMs on stator and the rotor PMs can be magnetized along the same direction or along different directions; in addition, there are also two magnetization patterns for the two tangentially magnetized PMs in the PM array. Thus, there are eight different magnetization patterns for the proposed machine, as illustrated in Figure 5. It can be observed from Figure 5 that row 1 is mirrored to row 2, i.e., the flux will be identical except that the flux direction is reversed. Hence, we just need to study the above magnetization patterns. Figure 6a gives waveforms of single-phase back electromotive forces (back EMFs) when the proposed machine adopts magnetization pattern A, B, C and D. Figure $6 \mathrm{~b}$ displays corresponding RMS and THD. It can be seen from Figure 6 that the proposed machine with pattern A can offer the largest back EMF with the smallest THD. Hence, magnetization pattern A is the optimal choice when designing the proposed machine. Meanwhile the proposed machine with magnetization pattern A in Figure 1 is chosen for study later in this paper.

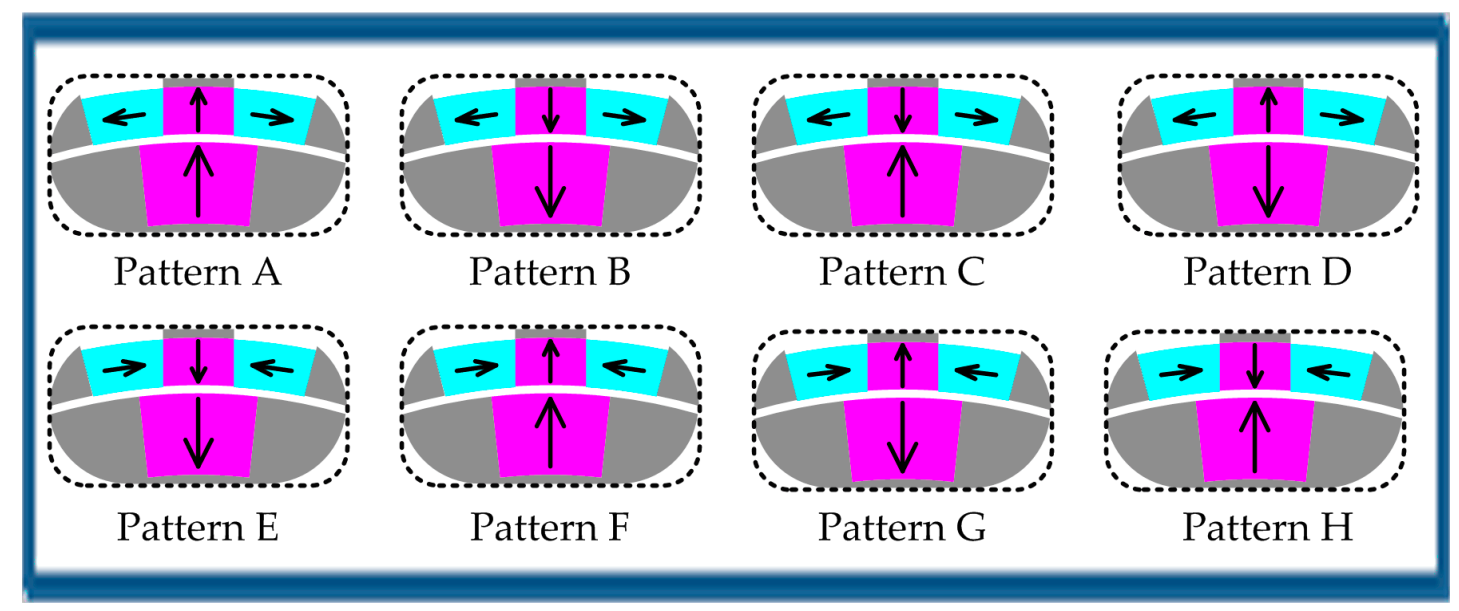

Figure 5. Different magnetization patterns. 


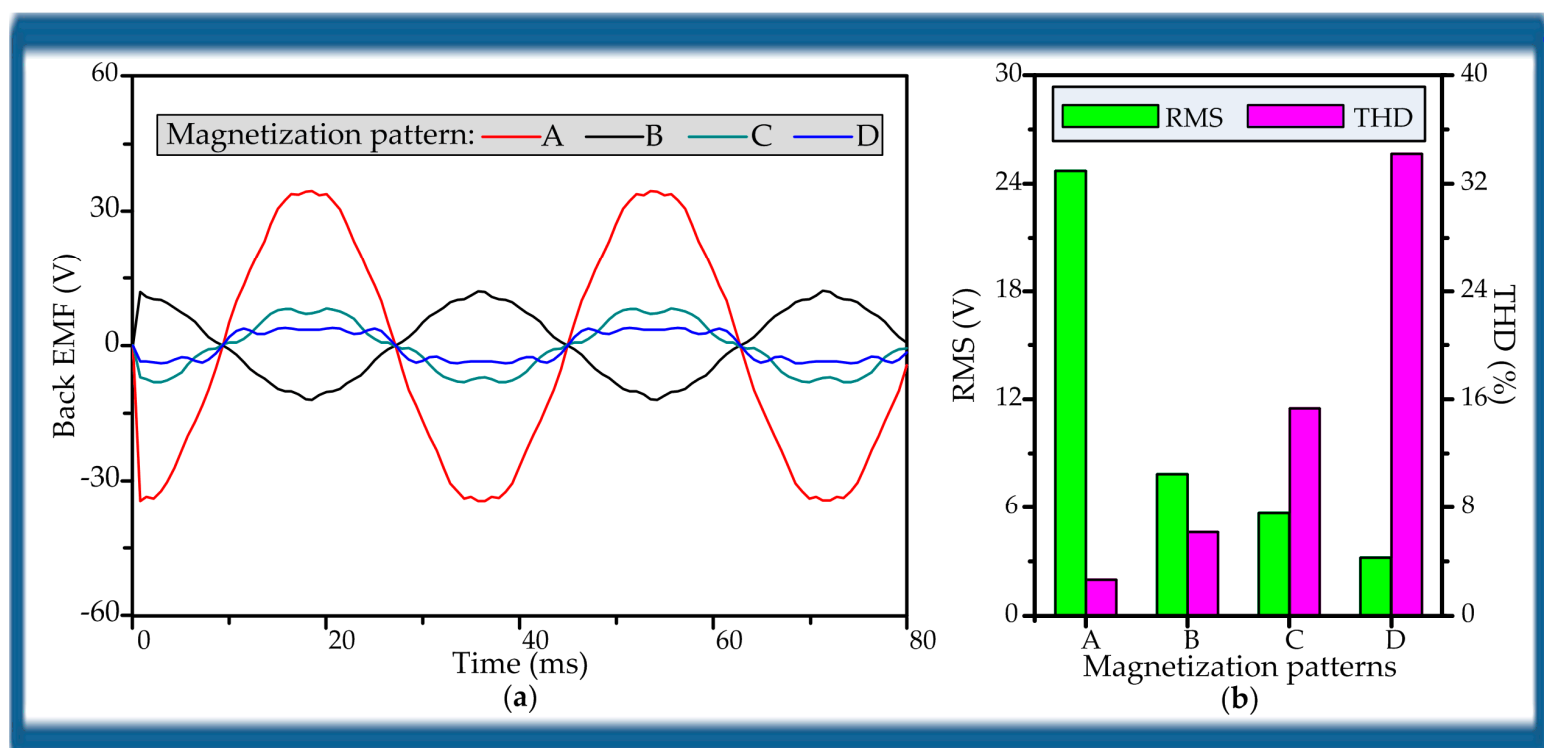

Figure 6. Single-phase back EMFs with different magnetization patterns: (a) Back EMF waveforms;

(b) Corresponding RMS and THD.

\subsection{Electromagnetic Performance Analysis}

Figures 7-9 illustrate the analysis of the magnetic field excited only by rotor PMs, stator PMs, and armature windings, which is obtained by using FEM. It can be observed from Figure 7a, Figure 8a, and Figure $9 \mathrm{a}$ that although the PPNs of the rotor PMs $\left(p_{1}=14\right)$ and stator PMs $\left(p_{2}=12\right)$ are not equal to the PPN of the armature windings $\left(p_{3}=2\right)$, the PPNs of the two sets of PMs after field modulation are the same as the PPN of the armature windings. Seeing from Figure $7 b$, Figure $8 b$, and Figure $9 b$, due to the BFME, the air-gap magnetic fields excited by the three field sources are very irregular, especially the magnetic field that is excited by the armature windings. The waveforms of the flux density imply that there are abundant field harmonics in the air-gap. Figure 7c, Figure $8 c$, and Figure $9 c$ give the corresponding harmonic spectrum. It can be seen that there are really a lot of harmonic components in the air-gap. Moreover, the harmonic components with exactly the same PPN and rotational speed are highlighted with the same color in the three figures, which agrees very well with the abovementioned analysis in Table 4.

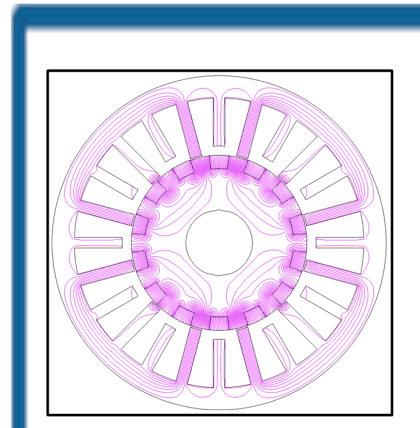

(a)

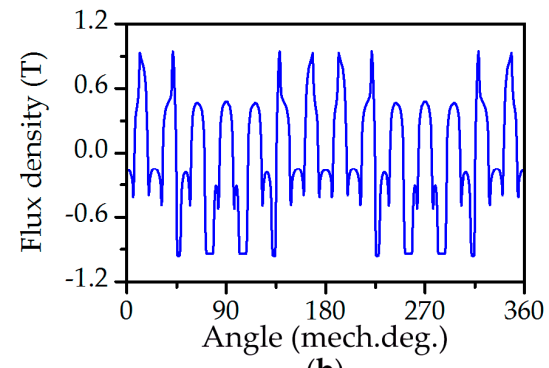

(b)

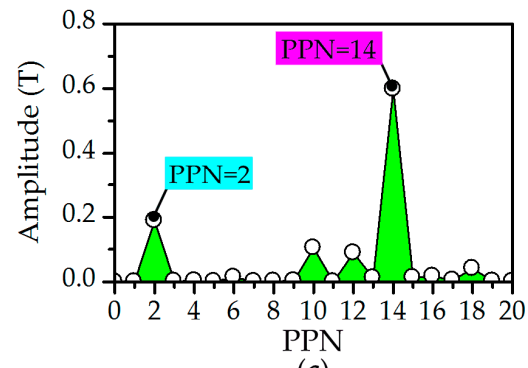

(c)

Figure 7. Analysis of magnetic field excited only by rotor PMs: (a) Flux lines distribution; (b) Flux density in the air-gap; and, (c) Harmonic spectrum. 


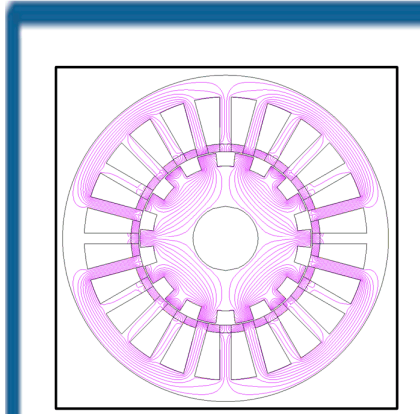

(a)

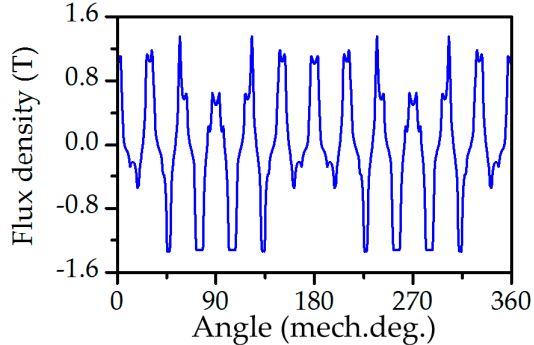

(b)

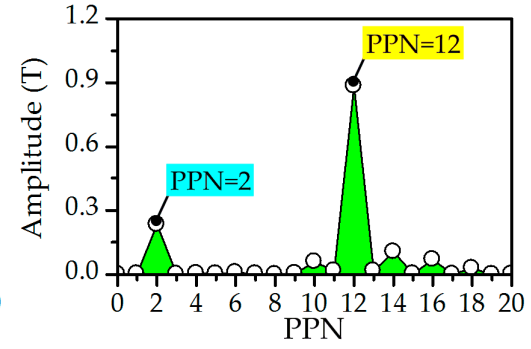

(c)

Figure 8. Analysis of magnetic field excited only by stator PMs: (a) Flux lines distribution; (b) Flux density in the air-gap; and, (c) Harmonic spectrum.

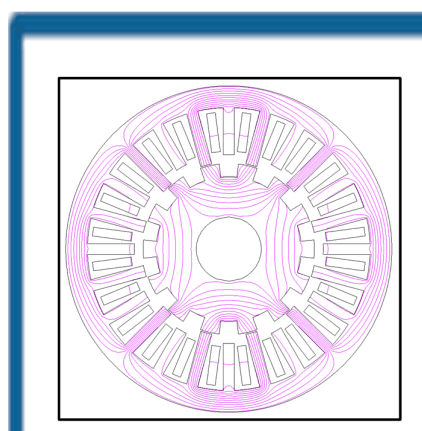

(a)

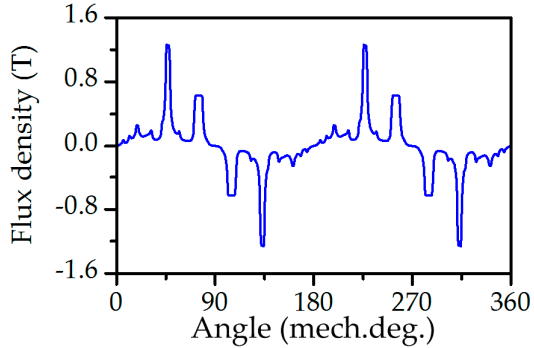

(b)

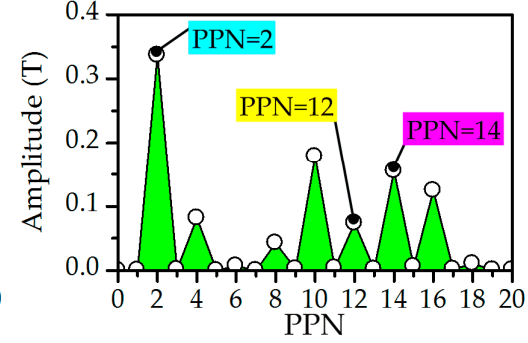

(c)

Figure 9. Analysis of magnetic field excited only by armature windings: (a) Flux lines distribution; (b) Flux density in the air-gap; and (c) Harmonic spectrum.

Figure 10 shows the air-gap relative permeability due to stator iron teeth calculated by FEM. One can find that the amplitude with Order $=24$ is smaller than that with Order $=12$. It indicates that despite the stator having twenty four iron teeth, only half the number of the stator iron teeth are mainly serving as field modulating teeth, which is consistent with the analysis in Section 2. Figure 11a shows the cogging torque when the rotor turns 90 degrees, and the maximum value is about $0.88 \mathrm{Nm}$. Figure $11 \mathrm{~b}$ gives the three-phase back EMF waveforms when the machine rotates at the speed of $120 \mathrm{r} / \mathrm{min}$. It can be obtained from Figure $11 \mathrm{~b}$ that the frequency of the back EMFs is about $28 \mathrm{~Hz}$.

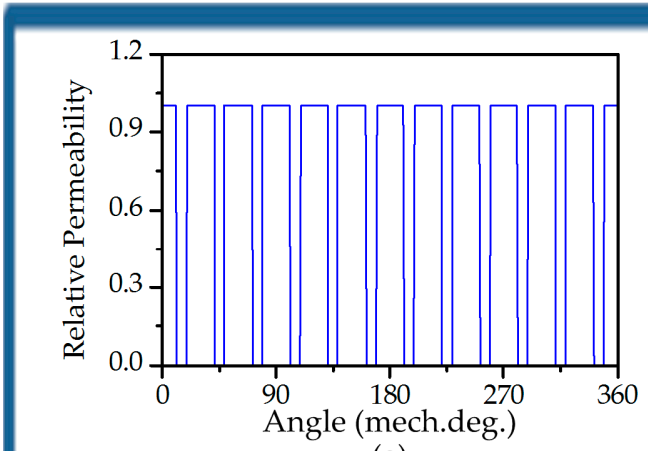

(a)

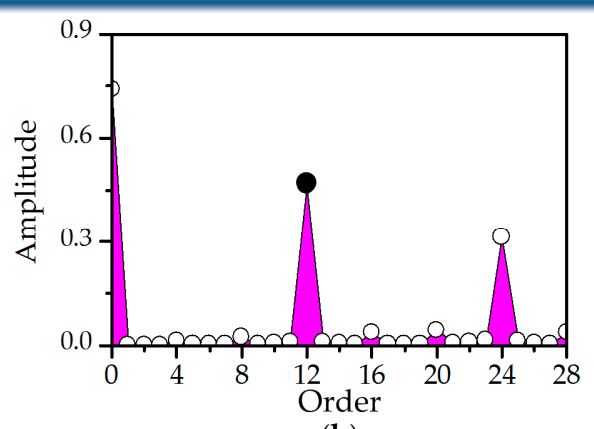

(b)

Figure 10. Air-gap relative permeability due to stator iron teeth: (a) Waveforms of relative permeability; and (b) Corresponding harmonic spectrum. 


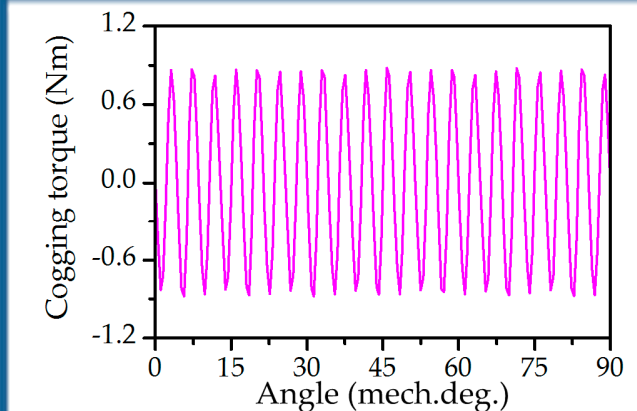

(a)

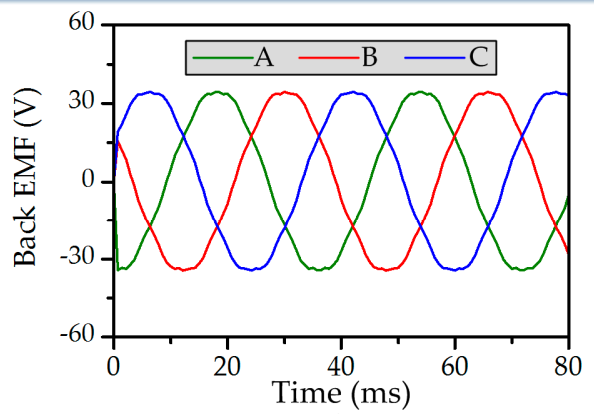

(b)

Figure 11. Proposed DPME machine: (a) Cogging torque; (b) Back EMF.

In order to assess the torque capability, blocking torque versus angle in Figure 12a is obtained by keeping the rotor at a standstill, and then injecting three-phase sinusoidal currents with $I=3 \mathrm{~A}$ into the armature windings. The maximum torque that the machine can offer is $17.27 \mathrm{Nm}$. Keeping the rotor at a constant speed and injecting three-phase sinusoidal currents with $I=3 \mathrm{~A}$ into the armature windings, the stable torque-time curve when the proposed machine outputs maximum torque can be obtained, as shown in Figure 12b. It can be known that the average torque offered by the machine is $17.39 \mathrm{Nm}$ and the torque ripple ratio is about $7.15 \%$.

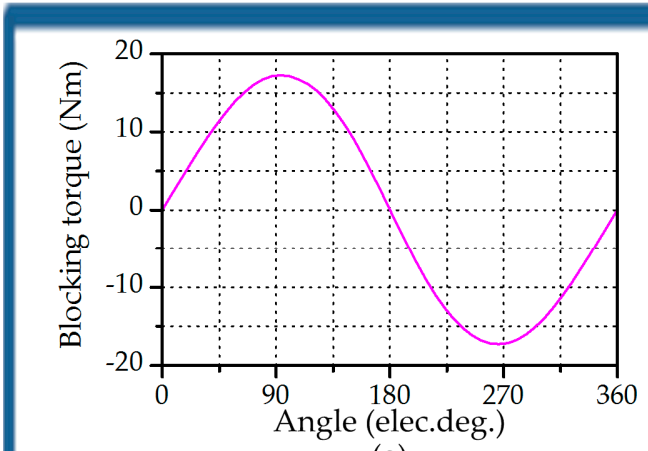

(a)

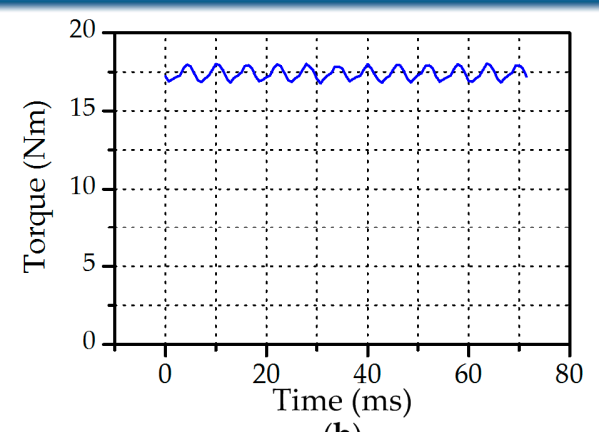

(b)

Figure 12. Proposed DPME machine with $I=3$ A: (a) Blocking torque; and, (b) Maximum torque.

Figure 13a exhibits the phase voltage and phase current waveforms when the proposed machine outputs the maximum torque with $I=3 \mathrm{~A}$. Since the waveform of the phase voltage is not a standard sine wave, the phase angle difference between the two waveforms can be calculated by FFT. It can be found from Figure $13 \mathrm{~b}$ that the power factor angle is 30.38 degree, which means that the power factor (PF) is about 0.86 . The loss of the proposed machine can be also obtained by 2D FEM in Jmag-Designer software. Figure 14 displays the loss of the each part when the three-phase sinusoidal currents with $I=3 \mathrm{~A}$ are injected into the windings, and the machine rotates at the speed of $120 \mathrm{r} / \mathrm{min}$. It is evident that for the machine, the total PM loss accounts for a small part in the total loss (0.73\%); the copper loss accounts for a considerable proportion in the total loss (84\%); and, the dominant iron loss is concentrated on the stator. 


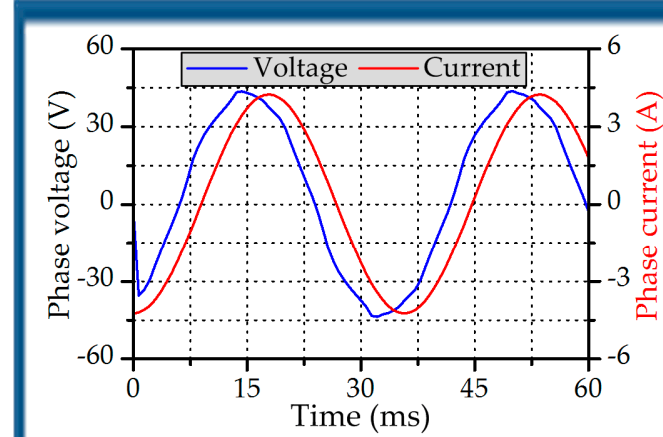

(a)

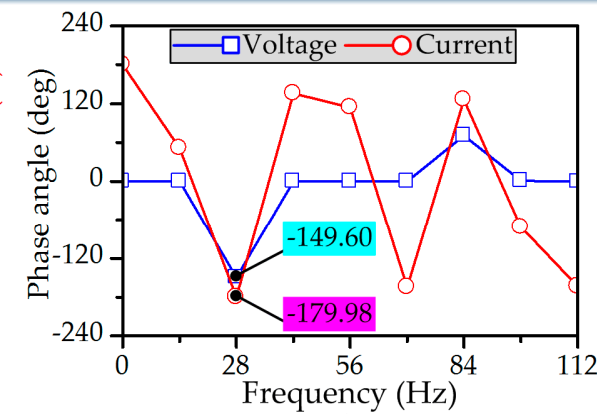

(b)

Figure 13. Proposed DPME machine: (a) Phase voltage and phase current waveforms; (b) Corresponding phase angle calculated by FFT.

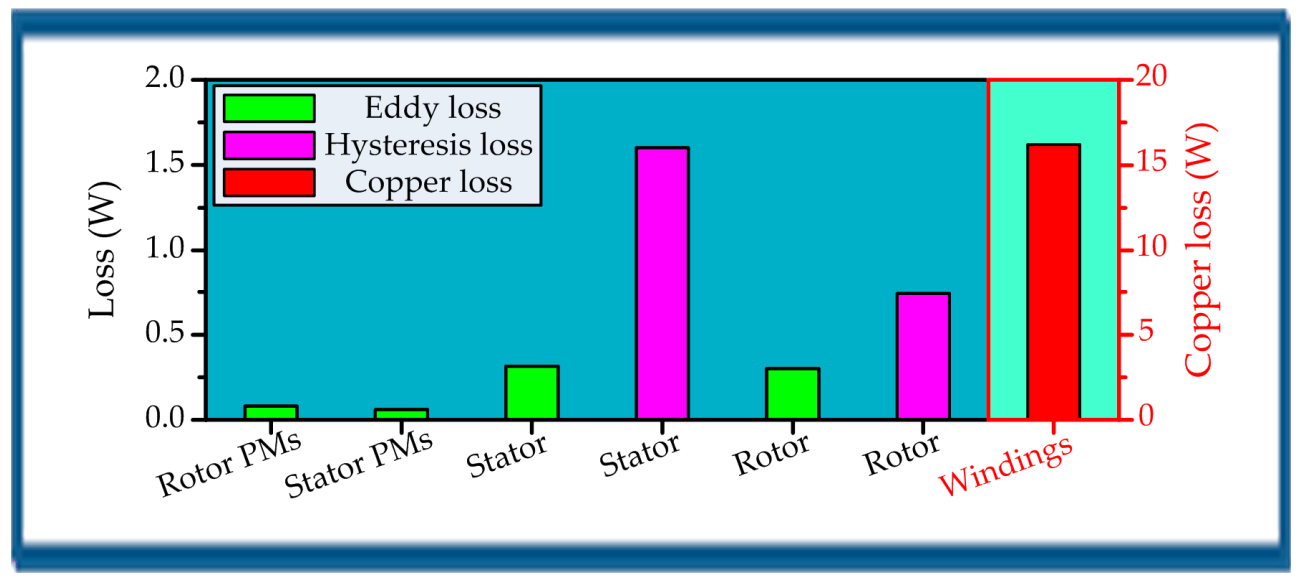

Figure 14. Loss when the proposed machine rotates at $120 \mathrm{r} / \mathrm{min}(I=3 \mathrm{~A})$.

Without considering the friction, windage and stray loss, the efficiency of the proposed machine can be evaluated by the formula below [37],

$$
\eta=\frac{T_{a} \Omega_{1}}{T_{a} \Omega_{1}+P_{\text {copper }}+P_{\text {iron }}+P_{P M}}
$$

where $T_{a}$ is the average torque; $P_{\text {copper, }} P_{\text {iron }}$ and $P_{P M}$ are copper loss, total iron loss and PM loss, respectively. Therefore, the efficiency of the proposed machine is about $92 \%$.

\section{Comparative Study}

As shown in Figure 15, two DPME machines are selected for comparative study. One is the proposed DPME machine with magnetization pattern A, and the other one is from [38]. It can be found from Figure 15 that Machine I can be obtained by removing the tangentially magnetized PMs, and it is fortunate that we can easily ensure that the two machines have the same the size, the same winding connection, the same electric load, and the same PPN combination of stator PMs and rotor PMs for fair comparison. The simulation models of Machine I are built based on the parameters in Table 5 . The simulation models of them have the same mesh.

Since Machine I has the same stator core, armature windings, rotor core and rotor PMs as the proposed machine, the magnetic fields excited only by rotor PMs and armature windings are the same as the proposed machine in Figures 7 and 9. Figure 16 compares the magnetic fields excited only by stator PMs between the two machines. It can be seen that the magnetic field of the proposed machine 
is stronger than Machine I due to flux strengthening effect arising from the arrangement of a long stator iron tooth and two tangentially magnetized PMs.

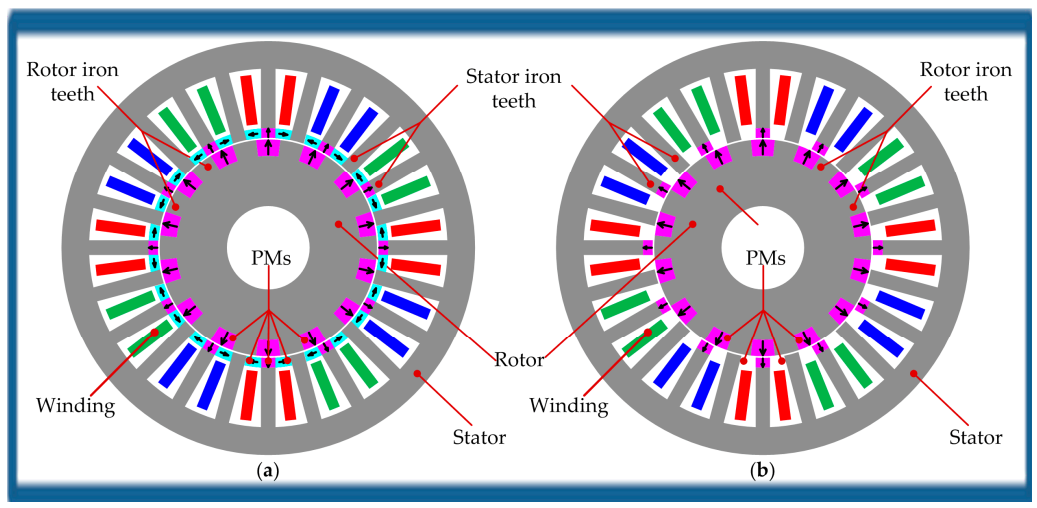

Figure 15. DPME Machines for comparison: (a) Proposed machine; and, (b) Machine I.

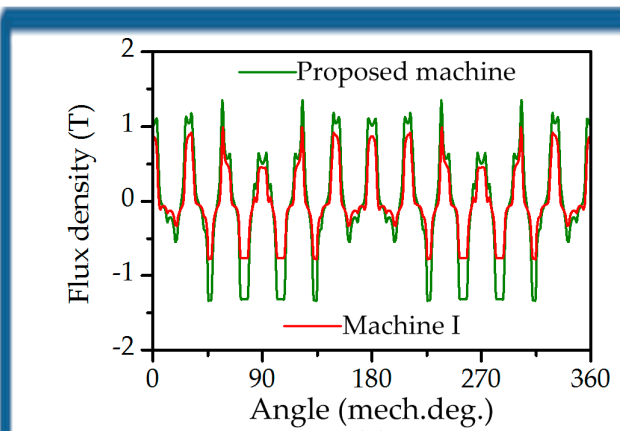

(a)

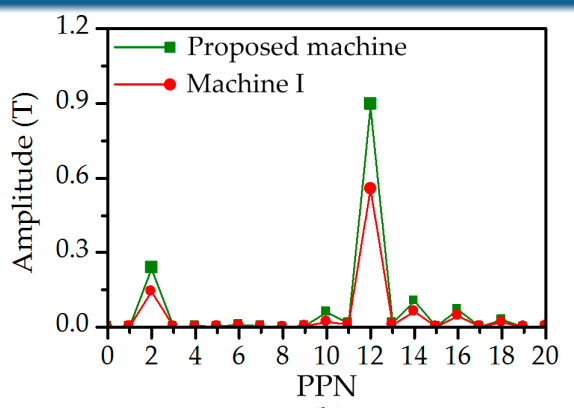

(b)

Figure 16. Comparison of magnetic fields excited only by stator PMs: (a) Flux density in the air-gap; (b) Corresponding harmonic spectrum.

Figure 17a compares their cogging torques when the rotor turns 90 degrees and the maximum value of the proposed machine and Machine I is $0.88 \mathrm{Nm}$ and $0.21 \mathrm{Nm}$, respectively. Apparently, the proposed machine has much larger cogging torque than Machine I. Figure $17 \mathrm{~b}$ compares phase back EMFs with the two machines at the speed of $120 \mathrm{r} / \mathrm{min}$. As can be seen, both the machines have the same electric cycle, and the amplitude of the proposed machine is larger than that of Machine I. Moreover, THD of the back EMF can be obtained by post processing and THD of the proposed machine and Machine I is $2.63 \%$ and $7.69 \%$, respectively. Hence, it can be concluded that the proposed machine can offer larger back EMF with smaller THD in comparison with Machine I.

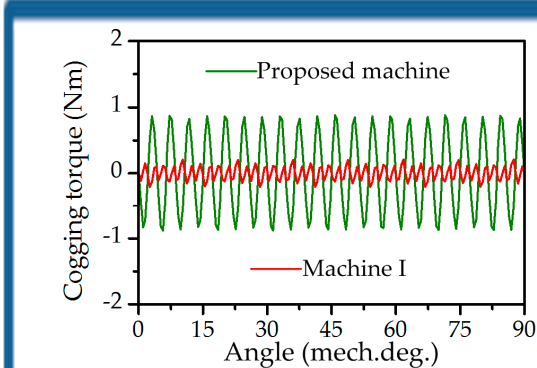

(a)

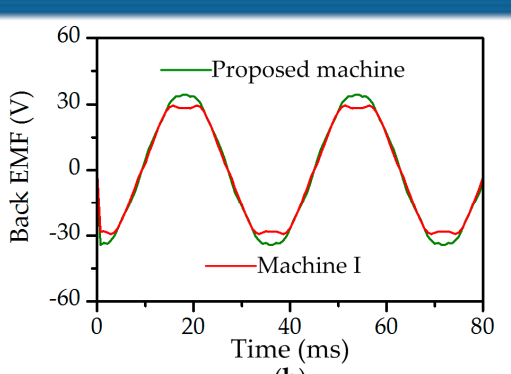

(b)

Figure 17. Performance comparison: (a) Cogging torque; and, (b) Phase back EMF. 
Figure 18a compares the torque capability of the two machines with the same current. It is evident that the proposed machine can offer larger torque than Machine I due to the BFME and flux strengthening effect. Figure $18 \mathrm{~b}$ gives the stable torque-time curves when three-phase currents with $I=3 \mathrm{~A}$ are injected into the two machines and both of them rotate at $120 \mathrm{r} / \mathrm{min}$. It can be known that the average torque that is offered by the proposed machine and Machine I is $17.39 \mathrm{Nm}$ and $14.99 \mathrm{Nm}$, respectively. Moreover, the torque ripple ratios of the two machines are listed in Table 6 . It can be observed that the proposed machine can offer larger torque with smaller torque ripple. Table 6 also lists the PF angle and PF when three-phase currents with $I=3 \mathrm{~A}$ are injected into the two machines and both of them rotate at $120 \mathrm{r} / \mathrm{min}$. Apparently, the PF of the proposed machine is also larger than Machine I. But, when compared with the conventional PM synchronous machine (PMSM), the PFs of them are really poor.

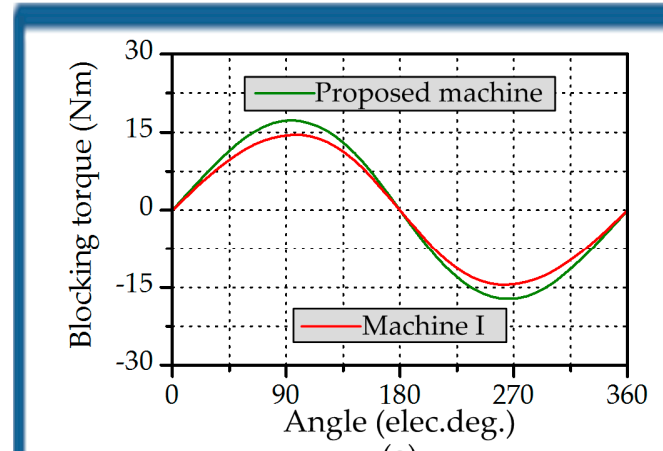

(a)

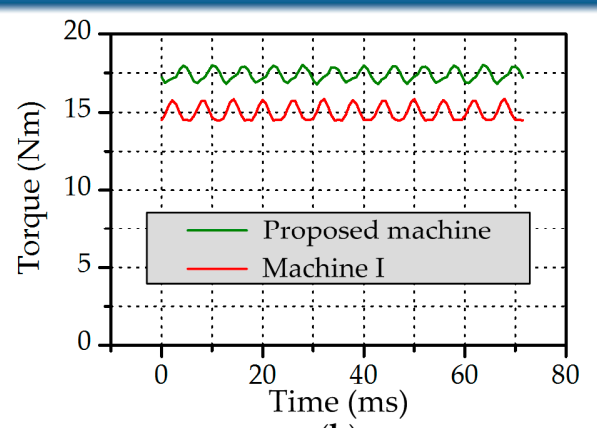

(b)

Figure 18. Performance comparison: (a) Blocking torque with $I=3 \mathrm{~A}$; (b) Maximum torque with $I=3 \mathrm{~A}$.

Table 6. Torque ripple ratio and PF comparison.

\begin{tabular}{cccc}
\hline Machines for Comparsion & Torque Ripple Ratio & PF Angle & PF \\
\hline Proposed machine & $7.15 \%$ & 30.38 degree & 0.86 \\
Machine I & $9.16 \%$ & 34.78 degree & 0.82 \\
\hline
\end{tabular}

Figure 19 evaluates the losses of the two machines when they rotate at $120 \mathrm{r} / \mathrm{min}$ and output the maximum torque with $I=3 \mathrm{~A}$. It can be observed that the copper losses of the two machines are the same, because they with the same phase resistance are injected the same current. The copper loss is $16.2 \mathrm{~W}$. Apart from the copper loss, the loss that is generated by each part in the proposed machine is a bit larger when compared with Machine I. In terms of each machine, the dominant iron loss is concentrated on the stator; the PM loss accounts for a small part in the total loss; the copper loss accounts for a considerable proportion in the total loss. The total loss of the proposed machine, Machine I is about $19.30 \mathrm{~W}, 18.75 \mathrm{~W}$, respectively. Meanwhile, the corresponding efficiency is $92 \%$, $91 \%$, respectively. So, it can be known that although the total loss in the proposed machine is a bit larger than Machine I, the efficiency of the proposed machine is a bit higher than Machine I, because it can offer larger torque with the BFME and flux strengthening effect.

The comparative results are summarized in Table 7 in order to make them clear. It can be seen that the electric load and speed of the two machines are the same, but the proposed DPME machine outperforms Machine I in many ways due to the BFME and flux strengthening effect. In terms of torque capability, the proposed machine can offer larger torque density than Machine I. But, the intensity of PM utilization in the proposed machine is a bit higher than Machine I. 


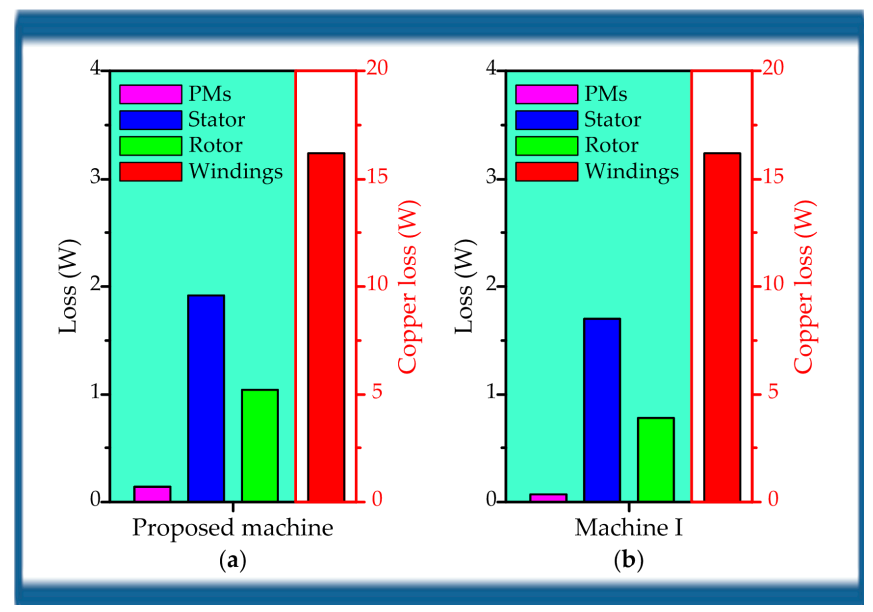

Figure 19. Loss comparison when two machines rotate at $120 \mathrm{r} / \mathrm{min}(I=3 \mathrm{~A})$ : (a) Proposed machine; (b) Machine I.

Table 7. Comparison results of the two machines.

\begin{tabular}{ccc}
\hline $\boldsymbol{I}=\mathbf{3}$ A, $\mathbf{1 2 0}$ r/min & Proposed Machine & Machine I \\
\hline Rated power & $218 \mathrm{~W}$ & $188 \mathrm{~W}$ \\
Rated phase voltage & $45 \mathrm{~V}$ & $40 \mathrm{~V}$ \\
Peak of cogging torque/back EMF & $0.88 \mathrm{Nm} / 34.45 \mathrm{~V}$ & $0.21 \mathrm{Nm} / 29.37 \mathrm{~V}$ \\
THD of back EMF & $2.63 \%$ & $7.69 \%$ \\
Rated torque & $17.39 \mathrm{Nm}$ & $14.99 \mathrm{Nm}$ \\
Torque ripple ratio & $7.15 \%$ & $9.16 \%$ \\
Power factor & 0.86 & 0.82 \\
Efficiency & $92 \%$ & $91 \%$ \\
Torque density & $17.08 \mathrm{kNm} / \mathrm{m}^{3}$ & $14.72 \mathrm{kNm} / \mathrm{m}^{3}$ \\
Intensity of PM utilization & $2.86 \mathrm{~kg} / \mathrm{kW}$ & $2.17 \mathrm{~kg} / \mathrm{kW}$ \\
\hline
\end{tabular}

\section{Conclusions}

In this paper, a novel DPME machine has been proposed. It adopts two sets of PMs, one is on the rotor and the other is on the stator with PM arrays. In particular, not all of the PMs in the arrays are in the stator slots. The radially magnetized PMs in the arrays are located under the short iron teeth, while the tangentially magnetized PMs are located in the slots that are formed by the long stator iron teeth and the radially magnetized PMs. Each long stator iron tooth is sandwiched by two tangentially magnetized PMs with opposite directions, hence resulting in the flux strengthening effect. Due to the flux strengthening effect and BFME, the proposed machine is better than Machine I in many ways. In terms of torque capability, the proposed machine can offer larger torque density than Machine I, but the intensity of PM utilization in the proposed machine is a bit higher than Machine I. Moreover, this paper has pointed out that magnetization patterns $\mathrm{A}$ is the best choice when designing the proposed DPME machine. Simulation results have verified the above conclusions.

Acknowledgments: This work was supported in part by the key program of National Natural Science Foundation of China under Grant 51377158, by the Natural Science Foundation of Guangdong Province under Project 2014A030306034, 2015TQ01N332, and by the Science and Technology Innovation Committee of Shenzhen under Projects ZDSYS201604291912175.

Author Contributions: All authors have contributed to this work. Linni Jian proposed the configuration of the investigated machine, conceived the outline of this paper and designed the experiments; Yujun Shi was mainly responsible for performing the experiments designed by Linni Jian, processing the data and wrote this paper.

Conflicts of Interest: The authors declare no conflict of interest. 


\section{References}

1. Li, X.L.; Chau, K.T.; Cheng, M.; Kim, B.; Lorenz, R.D. Performance analysis of a flux-concentrating field-modulated permanent-magnet machine for direct-drive applications. IEEE Trans. Magn. 2015, $51,8104911$.

2. Niu, S.X.; Ho, S.L.; Fu, W.N. A novel stator and rotor dual PM vernier motor with space vector pulse width modulation. IEEE Trans. Magn. 2014, 50, 805-808. [CrossRef]

3. Gao, Y.T.; Qu, R.H.; Li, D.W.; Chen, F.X. Force ripple minimization of a linear vernier permanent magnet machine for direct-drive servo applications. IEEE Trans. Magn. 2017, 53, 7001905. [CrossRef]

4. Li, X.L.; Chau, K.T.; Wang, Y.B. Modeling of a field-modulated permanent-magnet machine. Energies 2016, 9, 1078. [CrossRef]

5. Liu, J.; Zhao, W.X.; Ji, J.H.; Liu, G.H.; Tao, T. A novel flux focusing magnetically geared machine with reduced eddy current loss. Energies 2016, 9, 904. [CrossRef]

6. Feng, N.J.; Yu, H.T.; Hu, M.Q.; Liu, C.Y.; Huang, L.; Shi, Z.C. A study on a linear magnetic-geared interior permanent magnet generator for direct-drive wave energy conversion. Energies 2016, 9, 487. [CrossRef]

7. Liu, G.H.; Jiang, Y.C.; Ji, J.H.; Chen, Q.; Yang, J.Q. Design and analysis of a new fault-tolerant magnetic-geared permanent-magnet motor. IEEE Trans. Appl. Supercond. 2014, 24, 0503205.

8. Liu, C.H.; Yu, J.C.; Lee, C.H.T. A new electric magnetic-geared machine for electric unmanned aerial vehicles. IEEE Trans. Magn. 2017, 53, 8111306. [CrossRef]

9. Liu, C.H.; Chau, K.T.; Lin, F. A new hybrid-structure machine with multimode fault-tolerant operation for Mars Rover. IEEE Trans. Magn. 2015, 51, 8207904. [CrossRef]

10. Liu, C.H.; Chau, K.T.; Qiu, C. Design and analysis of a new magnetic-geared memory machine. IEEE Trans. Appl. Supercond. 2014, 24, 0503005.

11. Liu, C.H.; Chau, K.T. Electromagnetic design of a new electrically controlled magnetic variable-speed gearing machine. Energies 2014, 7, 1539-1554. [CrossRef]

12. Jiang, D.; Chang, J. Influences of winding MMF harmonics on torque characteristics in surface-mounted permanent magnet vernier machines. Energies 2017, 10, 580. [CrossRef]

13. Kim, B. Investigation on slot-pole combinations of a PM vernier motor with fractional-slot concentrated winding configurations. Energies 2017, 10, 1310. [CrossRef]

14. Kim, B.; Lipo, T.A. Operation and design principles of a PM vernier motor. IEEE Trans. Ind. Appl. 2014, 50, 3656-3663. [CrossRef]

15. Zhao, W.X.; Zheng, J.Q.; Wang, J.B.; Liu, G.H.; Zhao, J.X.; Fang, Z.Y. Design and analysis of a linear permanent-magnet vernier machine with improved force density. IEEE Trans. Ind. Electron. 2016, 63, 2246-2257. [CrossRef]

16. Xu, L.; Liu, G.H.; Zhao, W.X.; Yang, X.Y.; Cheng, R. Hybrid stator design of fault-tolerant permanent-magnet vernier machines for direct-drive applications. IEEE Trans. Ind. Electron. 2017, 64, 179-190. [CrossRef]

17. Xu, L.; Liu, G.H.; Zhao, W.X.; Ji, J.H. Stator-excited vernier high-temperature superconducting machine for direct drive propulsion. IEEE Trans. Appl. Supercond. 2016, 26, 5207505. [CrossRef]

18. Jia, S.F.; Qu, R.H.; Li, J.; Li, D.W.; Kong, W.B. A stator-PM consequent-pole vernier machine with hybrid excitation and DC-biased sinusoidal current. IEEE Trans. Magn. 2017, 53, 8105404. [CrossRef]

19. Du, Y.; Cheng, M.; Chau, K.T.; Liu, X.X.; Xiao, F.; Zhao, W.X.; Shi, K.; Mo, L.H. Comparison of linear primary permanent magnet vernier machine and linear vernier hybrid machine. IEEE Trans. Magn. 2014, 50, 8202604. [CrossRef]

20. Ji, J.H.; Zhao, J.X.; Zhao, W.X.; Fang, Z.Y.; Liu, G.H.; Du, Y. New high force density tubular permanent-magnet motor. IEEE Trans. Appl. Supercond. 2014, 24, 5200705.

21. Yang, H.; Lin, H.Y.; Zhu, Z.Q.; Fang, S.H.; Huang, Y.K. A dual-consequent-pole vernier memory machine. Energies 2016, 9, 134. [CrossRef]

22. Hosoya, R.; Shimomura, S. Apply to in-wheel machine of permanent magnet vernier machine using NdFeB bonded magnet-Fundamental study. In Proceedings of the 2011 IEEE 8th International Conference on Power Electronics and ECCE Asia (ICPE \& ECCE), Jeju, Korea, 30 May-3 June 2011; pp. 2208-2215.

23. Hosoya, R.; Hosoya, R.; Shimomura, S. Design of a ferrite magnet vernier machine for an in-wheel machine. In Proceedings of the 2011 IEEE Energy Conversion Congress and Exposition (ECCE), Phoenix, AZ, USA, 17-22 September 2011; pp. 2790-2797. 
24. Kazuhiro, S.; Shimada, H.; Shimomura, S. Design of NdFeB bond magnets for in-wheel permanent magnet vernier machine. In Proceedings of the 2012 15th International Conference on Electrical Machines and Systems (ICEMS), Sapporo, Japan, 21-24 October 2012; pp. 1-6.

25. Jian, L.N.; Shi, Y.J.; Liu, C.; Xu, G.Q.; Gong, Y.; Chan, C.C. A novel dual-permanent-magnet-excited machine for low-speed large-torque applications. IEEE Trans. Magn. 2013, 49, 2381-2384. [CrossRef]

26. Zhao, W.X.; Sun, X.J.; Ji, J.H.; Liu, G.H. Design and analysis of new vernier permanent-magnet machine with improved torque capability. IEEE Trans. Appl. Supercond. 2016, 26, 5201505. [CrossRef]

27. Shi, Y.J.; Niu, S.X.; Wei, J.; Jian, L.N.; Liu, R.F. Comparison between dual-permanent-magnet-excited machines with fewer stator poles and fewer rotor poles. IEEE Trans. Magn. 2014, 51, 8200604.

28. Jian, L.N.; Shi, Y.J.; Wei, J.; Zheng, Y.C.; Deng, Z.X. Design optimization and analysis of a dual-permanent-magnet-excited machine using response surface methodology. Energies 2015, 8, 10127-10140. [CrossRef]

29. Xie, K.F.; Li, D.W.; Qu, R.H.; Gao, Y.T. A novel permanent magnet vernier machine with Halbach array magnets in stator slot opening. IEEE Trans. Magn. 2017, 53, 7207005. [CrossRef]

30. Shi, C.J.; Li, D.W.; Qu, R.H.; Zhang, H.; Gao, Y.T.; Huo, Y.S. A novel linear permanent magnet vernier machine with consequent-pole permanent magnets and Halbach permanent magnet arrays. IEEE Trans. Magn. 2017, 53, 2501404. [CrossRef]

31. Jiang, D.K.; Chang, J.H. Design of a vernier machine with PM on both sides of rotor and stator. IEEE Trans. Magn. 2014, 50, 877-880. [CrossRef]

32. Riba, J.R.; López-Torres, C.; Romeral, L.; Garcia, A. Rare-earth-free propulsion motors for electric vehicles: A technology review. Renew. Sustain. Energy Rev. 2016, 57, 367-379. [CrossRef]

33. López-Torres, C.; Garcia, A.; Riba, J.R.; Romeral, L. Design and optimization for vehicle driving cycle of rare-earth-free SynRM based on coupled lumped thermal and magnetic networks. IEEE Trans. Veh. Technol. 2017, PP. [CrossRef]

34. Bonthu, S.S.R.; Islam, M.Z.; Choi, S. Design of a rare earth free external rotor permanent magnet assisted synchornous reluctance motor. In Proceedings of the 2017 IEEE International Electric Machines and Drives Conference (IEMDC), Miami, FL, USA, 21-24 May 2017; pp. 1-6.

35. López-Torres, C.; Dobromir, T.M.; Espinosa, A.G.; Martínez, L.R. Operational boundaries calculation of permanent magnet assisted synchronous reluctance motor. In Proceedings of the 2017 IEEE Industry Applications Society Annual Meeting, Cincinnati, OH, USA, 29 September-5 October 2017; pp. 1-7.

36. López-Torres, C.; Michalski, T.; Garcia Espinosa, A.; Romeral, L. Fast optimization of the magnetic model by means of reluctance network for PMa-SynRM. In Proceedings of the IECON 2016-42nd Annual Conference of the IEEE Industrial Electronics Society, Florence, Italy, 23-26 October 2016; pp. 1642-1647.

37. Xu, L.; Liu, G.H.; Zhao, W.X.; Ji, J.H.; Zhou, H.W.; Zhao, W.X.; Jiang, T.T. Quantitative comparison of integral and fractional slot permanent magnet vernier motors. IEEE Trans. Energy Convers. 2015, 30, 1483-1495. [CrossRef]

38. Wang, Q.S.; Niu, S.X. A novel hybrid-excited dual-PM machine with bidirectional flux modulation. IEEE Trans. Energy Convers. 2017, 32, 424-435. [CrossRef]

(C) 2018 by the authors. Licensee MDPI, Basel, Switzerland. This article is an open access article distributed under the terms and conditions of the Creative Commons Attribution (CC BY) license (http://creativecommons.org/licenses/by/4.0/). 